\title{
Comment on: "Systematic Review of Economic Evaluations in Primary Open-Angle Glaucoma: Decision Analytic Modeling Insights"
}

\author{
Omar Salamanca ${ }^{1,2}$ (D) \\ Published online: 13 July 2020 \\ (c) The Author(s) 2020
}

\section{Dear Editor,}

I have read the paper "Systematic Review of Economic Evaluations in Primary Open-Angle Glaucoma: Decision Analytic Modeling Insights" by Bartelt-Hofer et al. [1]. The information reported is of the highest utility for guiding clinical behaviors, as well as for resource allocation and decision making regarding the benefit plans of health systems and insurers. In the results of Section 3.3, laser trabeculoplasty (LT), referencing the study by Stein et al., was cost-effective compared to observation only [2]. Additionally, two studies are referenced comparing LT with prostaglandin analogs, with findings that $\mathrm{LT}$ is a less expensive alternative, referencing Ordoñez et al. [3] and Stein et al. [2]. The study by Guedes et al. [4], which found LT to be cost-effective in mild and moderate glaucoma, was inadvertently left out of Section 3.3 of the review.

The study Guedes et al., from Brazil and published in 2016, is a cost-utility analysis (CUA) using a Markov model, with a lifetime horizon that includes quality-adjusted life years (QALYs), in patients with primary open-angle glaucoma (POAG). The study reviews different treatment strategies based on glaucoma severity to simulate the diagnosis of glaucoma over the average lifespan. Observation, medications, and laser treatment were compared in early glaucoma cases. For moderate glaucoma, a comparison was drawn between medications, laser treatment, and surgery. For advanced glaucoma, only medications and surgery were compared. The types of laser included argon laser

This comment refers to the article available online at https://doi. org/10.1007/s41669-019-0141-4.

Omar Salamanca

omarsalamancamd@gmail.com

1 Department of Ophthalmology, Universidad del Valle, Cali, Colombia

2 Orbis International, New York, USA trabeculoplasty (ALT) and selective laser trabeculoplasty (SLT), but there was no distinction between the two types of lasers in the study. In early glaucoma, medication and LT were found to be highly cost-effective; this effect is greater when LT is started earlier in life. The incremental cost-effectiveness ratio (ICER) was US $\$ 1056 /$ QALY for laser treatment and US\$1297/QALY for medications. For moderate glaucoma, laser treatment was the second most cost-effective treatment after surgery [4].

The CUA study by Stein et al. from USA in 2012, included patients aged 60 years, newly diagnosed with open-angle glaucoma (OAG), using a Markov model with a 25-year time horizon. They compared observation with prostaglandin analog treatment or LT (ALT or SLT). The results showed an incremental cost-effectiveness of LT compared to no treatment of US\$16,842/QALY and the incremental cost-effectiveness of prostaglandin analogs compared to no treatment of US\$14,179/QALY. However, the sensitivity analysis showed that if the prostaglandin analogs were $25 \%$ less effective (for example, due to poor adherence) or if the LT was $20 \%$ more effective than reported in the Glaucoma Laser Trial (a randomized clinical trial [RCT] conducted over 25 years ago), LT could be the preferred option [2].

The other study, published by Ordoñez et al. in 2019, was a CUA using a Markov model, with a lifetime horizon in Colombia. It included patients over 40 years of age diagnosed with OAG staged from zero (ocular hypertension without glaucoma) to five and bilateral blindness who were receiving at least one medication. The comparison alternatives were micro-bypass trabecular stent + timolol, SLT + timolol + dorzolamide, latanoprost + timolol + dorzolamide, bimatoprost + timolol + dorzolamide, and travoprost + timolol + dorzolamide. Observation or standard surgery (trabeculectomy) were not included in the comparison. The investigators reported QALYs, and the risk of hip fracture (due to the loss of visual acuity) was included in the model as a clinical outcome. LT plus medication was found 
to be the second option with respect to QALYs, following micro-bypass trabecular stent + timolol [3].

It is well known that updating a systematic review is very time consuming and generally only recommended when conflicting evidence is released. I would like to draw your attention to new evidence that could be included in an updated systematic review. When reviewing the evidence with respect to the economic evaluations of glaucoma, especially when reviewing LT, the LiGHT study should also be included [5]. This study from the UK reported the results of an RCT in patients with OAG or ocular hypertension. SLT followed by medical treatment was compared to medical treatment only. This study made an economic evaluation of the CUA type that calculated the incremental mean cost per QALY between the treatment alternatives. A Markov statetransition model was used. The time horizon for the model was a lifetime. It was found that SLT provides superior stability compared to medications alone. Nearly three-quarters of patients were satisfactorily controlled without drops for at least 3 years and had a higher safety profile than previously reported. The economic evaluation found that there was a $97 \%$ probability that SLT is more cost-effective than medicine, at a willingness to pay for a QALY of $£ 20,000$, with a reduction in ophthalmology costs. The study indicated that SLT is cost-effective over a period of 3 years and it is highly likely that it will remain cost-effective for the life of the patients [6]. Data from this study was released in March and June 2019, after the literature search for the systematic review by Bartelt-Hofer et al. [1]. The importance of these results for the management of glaucoma lies in the high methodological quality of the RCT and the associated economic evaluation. It is likely that this study will outline management strategies for patients with glaucoma in future studies [7]. Regarding the use of SLT as a glaucoma treatment, more evidence has been published that corroborates its role as a first-line option [8]. It is worth considering the data brought forth in this letter when reviewing the findings of the recently published systematic review of economic evaluations in glaucoma [1]. Consider if the systematic review should be updated earlier, based on evidence released after the conclusions of the evaluation were drawn [9].

\section{Compliance with Ethical Standards}

Funding None.

Conflict of interest The author, Omar Salamanca, declares he has no conflicts of interest relevant to the contents of this letter.
Open Access This article is licensed under a Creative Commons Attribution-NonCommercial 4.0 International License, which permits any non-commercial use, sharing, adaptation, distribution and reproduction in any medium or format, as long as you give appropriate credit to the original author(s) and the source, provide a link to the Creative Commons licence, and indicate if changes were made. The images or other third party material in this article are included in the article's Creative Commons licence, unless indicated otherwise in a credit line to the material. If material is not included in the article's Creative Commons licence and your intended use is not permitted by statutory regulation or exceeds the permitted use, you will need to obtain permission directly from the copyright holder. To view a copy of this licence, visit http://creativecommons.org/licenses/by-nc/4.0/.

\section{References}

1. Bartelt-Hofer J, Ben-Debba L, Flessa S. Systematic review of economic evaluations in primary open-angle glaucoma: decision analytic modeling insights. Pharmacoecon Open. 2020;4(1):5-12. https://doi.org/10.1007/s41669-019-0141-4.

2. Stein JD, Kim DD, Peck WW, Giannetti SM, Hutton DW. Costeffectiveness of medications compared with laser trabeculoplasty in patients with newly diagnosed open-angle glaucoma. Arch Ophthalmol. 2012;130(4):497-505. https://doi.org/10.1001/archo phthalmol.2011.2727.

3. Ordóñez JE, Ordóñez A, Osorio UM. Cost-effectiveness analysis of iStent trabecular micro-bypass stent for patients with open-angle glaucoma in Colombia. Curr Med Res Opin. 2019;35(2):329-40. https://doi.org/10.1080/03007995.2018.1506022.

4. Guedes RA, Guedes VM, Gomes CE, Chaoubah A. Maximizing cost-effectiveness by adjusting treatment strategy according to glaucoma severity. Medicine (Baltimore). 2016;95(52):e5745. https://doi.org/10.1097/MD.0000000000005745.

5. Gazzard G, Konstantakopoulou E, Garway-Heath D, Garg A, Vickerstaff V, Hunter R, Ambler G, Bunce C, Wormald R, Nathwani N, Barton K, Rubin G, Buszewicz M, LiGHT Trial Study Group. Selective laser trabeculoplasty versus eye drops for first-line treatment of ocular hypertension and glaucoma (LiGHT): a multicenter randomised controlled trial. Lancet. 2019;393(10180):1505-16. https://doi.org/10.1016/S0140 $-6736(18) 32213-X$.

6. Gazzard G, Konstantakopoulou E, Garway-Heath D, Garg A, Vickerstaff V, Hunter R, Ambler G, Bunce C, Wormald R, Nathwani N, Barton K, Rubin G, Morris S, Buszewicz M. Selective laser trabeculoplasty versus drops for newly diagnosed ocular hypertension and glaucoma: the LiGHT RCT. Health Technol Assess. 2019;23(31):1-102. https://doi.org/10.3310/hta23310.

7. Young JW, Caprioli J. Laser trabeculoplasty as first-line glaucoma treatment. Lancet. 2019;393(10180):1479-80. https://doi. org/10.1016/S0140-6736(18)32553-4.

8. Chi SC, Kang YN, Hwang DK, Liu CJ. Selective laser trabeculoplasty versus medication for open-angle glaucoma: systematic review and meta-analysis of randomised clinical trials. $\mathrm{Br} \mathrm{J}$ Ophthalmol. 2020. https://doi.org/10.1136/bjophthalmol-2019-31561 3.

9. Bashir R, Surian D, Dunn AG. Time-to-update of systematic reviews relative to the availability of new evidence. Syst Rev. 2018;7(1):195. https://doi.org/10.1186/s13643-018-0856-9. 